\title{
TO ANALYSE THE CHOROIDAL THICKNESS IN DIFFERENT TRIMESTER OF UNCOMPLICATED PREGNANCY BY ENHANCED DEPTH IMAGING OPTICAL COHERENCE TOMOGRAPHY
}

\author{
Arpita De1, Ranabir Mazumdar ${ }^{2}$
}

${ }_{1}^{1}$ Postgraduate Trainee, Department of Ophthalmology, RIO, Medical College and Hospital, Kolkata.

2Postgraduate Trainee, Department of Ophthalmology, RIO, Medical College and Hospital, Kolkata.

\begin{abstract}
BACKGROUND

The ocular effects of pregnancy can be associated with development of new ocular pathology or may cause modification of preexisting conditions. Possible posterior segment changes include worsening of diabetic retinopathy, increased risk of peripheral vitreochorioretinal dystrophies, central serous chorioretinopathy and retinal detachment. Knowledge of the ocular changes that occur in association with pregnancy can help in the diagnosis and management of ocular disease in the pregnant women. Enhanced Depth Imaging Optical Coherence Tomography (EDI-OCT) is used currently to measure choroidal thickness. Histopathological examination showed that it is 0.22 um thick. Choroid thickness is affected by blood flow and perfusion pressure. Occlusion of choriocapillaries by a thrombus lead to disruption of overlying retinal pigment epithelium causing serous retinal detachment.
\end{abstract}

\section{AIMS AND OBJECTIVES}

To analyse subfoveal and parafoveal ( $3 \mathrm{~mm}$ away from fovea) choroidal thickness in uncomplicated pregnancy in different trimester by EDI-OCT.

\section{MATERIALS AND METHODS}

This study was done at the Regional Institute of Ophthalmology, Kolkata and Department of Obstetrics and Gynaecology, Medical College, Kolkata; 100 uncomplicated pregnant females in the age group of 20-40 years were followed up by EDI-OCT in all three trimesters for eighteen months. Refractive errors, best corrected visual activity, intraocular pressure and blood pressure measured in all cases.

\section{RESULTS}

The study shows that subfoveal choroidal thickness increased in second trimester in comparison to first trimester by means of $0.63 \mu \mathrm{m}$ in RE and $0.66 \mu \mathrm{m}$ in LE, but decreased in third trimester by mean of $1.31 \mu \mathrm{m}$ in RE and $1.82 \mu \mathrm{m}$ in LE. Mean inferior parafoveal choroidal thickness increased in second trimester by mean of $1.06 \mu \mathrm{m}$ in RE and $1.26 \mu \mathrm{m}$ in LE, but subsequently decreased in third trimester by mean of $1.98 \mu \mathrm{m}$ in RE and $2.3 \mu \mathrm{m}$ in LE. Mean superior parafoveal choroidal thickness increased in second trimester by mean of $1.00 \mu \mathrm{min} R E$ and $1.14 \mu \mathrm{min} \mathrm{LE}$, but subsequently decreased in third trimester in comparison to second trimester by mean of $2.07 \mu \mathrm{m}$ in RE and $2.26 \mu \mathrm{m}$ in LE. Mean nasal parafoveal choroidal thickness also significantly increased in second trimester by mean of $1.07 \mu \mathrm{m}$ in RE and $1.52 \mu \mathrm{m}$ in LE, but subsequently decreased in third trimester in by mean of $2.11 \mu \mathrm{m}$ in RE and $2.26 \mu \mathrm{m}$ in LE. Mean temporal parafoveal choroidal thickness also increased in second trimester by mean of $0.05 \mu \mathrm{m}$ in RE and $0.59 \mu \mathrm{m}$ in LE, but it decreased in third trimester by mean $1.44 \mu \mathrm{m}$ in RE and $1.88 \mu \mathrm{m}$ in LE.

\section{CONCLUSIONS}

The present study reports that the mean subfoveal and parafoveal ( $3 \mathrm{~mm}$ away from fovea) in all quadrants choroidal thickness increases in second trimester in comparison to first due to decreased peripheral vascular resistance, renin-angiotensin induced salt water retention from fifth week of gestation but as the pregnancy progresses it significantly decreases in third trimester due to oestrogen-induced peripheral vasodilatation, peripheral pooling of blood and decreased choroidal blood flow.

\section{KEYWORDS}

Enhanced Depth Imaging Optical Coherence Tomography, Retinal Pigment Epithelium, Subfoveal Choroidal Thickness, Intraocular Pressure, Refractive Error, Best Corrected Visual Acuity, Central Corneal Thickness.

HOW TO CITE THIS ARTICLE: De A, Mazumdar R. To analyse the choroidal thickness in different trimester of uncomplicated pregnancy by enhanced depth imaging optical coherence tomography. J. Evolution Med. Dent. Sci. 2016;5(80):6005-6008, DOI: $10.14260 /$ jemds/2016/1355

Financial or Other, Competing Interest: None.

Submission 14-09-2016, Peer Review 26-09-2016,

Acceptance 29-09-2016, Published 06-10-2016.

Corresponding Author:

Dr. Arpita De,

\#1/3, Olai Chandi Road, Tala, P.O-Belgachia

Kolkata-700037.

E-mail: arpitade17@gmail.com

DOI: $10.14260 /$ jemds/2016/1355

(c) (i) $\odot$

\section{INTRODUCTION}

Various hormonal, metabolic, haemodynamic and vascular changes occur in pregnancy. The ocular effects of pregnancy can be associated with development of new ocular pathology or may cause modification of pre-existing conditions. ${ }^{1}$ Possible posterior segment changes include worsening of diabetic retinopathy, ${ }^{2}$ increased risk of peripheral vitreochorioretinal dystrophies, central serous chorioretinopathy ${ }^{3}$ and retinal detachment. ${ }^{4}$ Knowledge of the ocular changes that occur in association with pregnancy 
can help in the diagnosis and management of ocular disease in the pregnant women. ${ }^{5}$

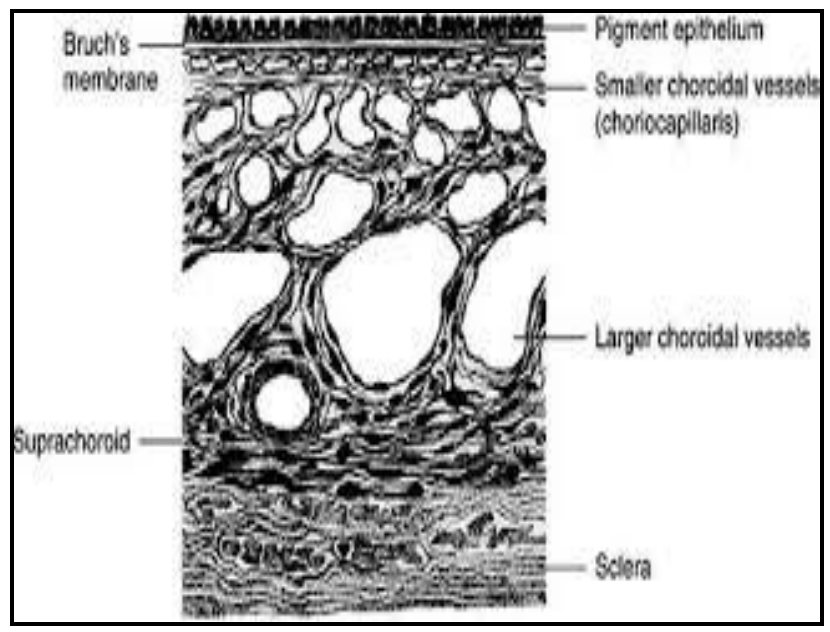

Fig. 1: Anatomy of Choroid

\section{AIMS AND OBJECTIVES}

To analyse choroidal thickness in uncomplicated pregnant females of age group 20-40 years using EDI-OCT technique and to follow up them for the next trimesters and to compare the values in three different trimesters.

\section{MATERIALS AND METHODS}

This study was done at the Regional Institute of Ophthalmology, Kolkata and Department of Obstetrics and Gynaecology, Medical College, Kolkata.

One hundred uncomplicated pregnant females in the age group of 20-40 years were followed up by EDI-OCT in all three trimesters at the Department of Obstetrics and Gynaecology, Medical College, Kolkata, for eighteen months. High myopia [ $>6$ Diopters of spherical equivalent], high IOP [ $>21 \mathrm{mmHg}$ ] as well as any ocular diseases that one known to affect choroidal thickness such as glaucoma, uveitis, retinal and choroidal inflammation are excluded from this study. Refractive Errors [RE], best corrected visual activity, Intraocular Pressure [IOP] and Blood Pressure [BP] measured in all cases. An auto refractometer, tonometer and sphygmomanometer used for measurement of Refractive Errors [RE], Intraocular Pressure [IOP] and Blood Pressure [BP] respectively. An anterior segment examination was done under slit lamp and posterior segments examination was done by $+90 \mathrm{D}$ lens under slit lamp biomicroscopy. The patients underwent EDI-OCT using the Spectralis Heidelberg apparatus [Heidelberg Engineering, Carlsbad, CA, USA]. In each patient, two perpendicular [horizontal and vertical] EDI - OCT scans made averaged 100 times centered on the fovea. These scans were marked as the patient's baseline and repeated at the second and third trimester on the same patients. In the horizontal and vertical macular scans, choroidal thickness measured manually using the callipes provided by the Spectralis Heidelberg software by EDI using spectral domain OCT through the center of the fovea and 3 $\mathrm{mm}$ away from the fovea in the cardinal directions [superior, inferior, nasal and temporal]. Choroidal thickness measured from the outer surface of the line formed by retinal pigment epithelium to the choroidoscleral interface using the spectralis OCT measurement software.
Subfoveal choroidal thickness calculated as the average of horizontal and vertical measurements and the changes in the subfoveal choroidal thickness were analysed. The subfoveal and parafoveal (3 $\mathrm{mm}$ away from the fovea) choroidal thickness were compared during the different trimester of pregnancy. IOP was measured by Goldmann applanation tonometer in each visit. All datas were expressed as the mean \pm standard deviation.

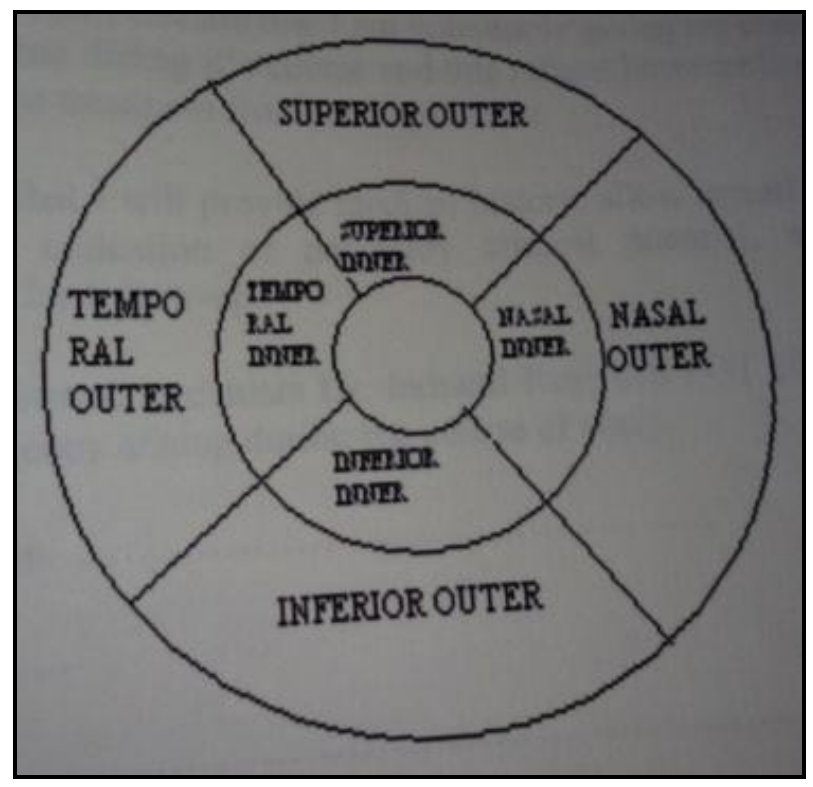

Fig. 2: Choroidal Thickness Measured Through the Center of the Fovea and $3 \mathrm{~mm}$ Away from the Fovea in the Cardinal Directions [Superior, Inferior, Nasal and Temporal]

\section{RESULTS AND ANALYSIS}

One hundred uncomplicated pregnant women in the age group of 20-40 years were recruited in our study. The mean subfoveal choroidal thickness in RE was $308.30 \mu \mathrm{m}$ (SD$\pm 2,096$, Range $304 \mu \mathrm{m}-312 \mu \mathrm{m}$ ) in first trimester, 308.93 $\mu \mathrm{m}$ (SD- \pm 2.011 , Range $305 \mu \mathrm{m}-312 \mu \mathrm{m}$ ) in second trimester and was $307.62 \mu \mathrm{m}$ (SD- \pm 2.024 , Range $303 \mu \mathrm{m}-311 \mu \mathrm{m}$ ) in third trimester. The mean subfoveal choroidal thickness in LE was $308.29 \mu \mathrm{m}$ (SD- $\pm 2,007$, Range $304 \mu \mathrm{m}-312 \mu \mathrm{m}$ ) in first trimester, $308.95 \mu \mathrm{m}$ (SD- \pm 1.925 , Range $305 \mu \mathrm{m}-312 \mu \mathrm{m}$ ) in second trimester and $307.13 \mu \mathrm{m}$ (SD- \pm 2.338 , Range 303 $\mu \mathrm{m}-311 \mu \mathrm{m})$ in third trimester. The study shows that subfoveal choroidal thickness increased in second trimester in comparison to first trimester by mean of $0.63 \mu \mathrm{m}$ in RE and $0.66 \mu \mathrm{m}$ in LE, but subsequently decreased in third trimester in comparison to second trimester by mean of $1.31 \mu \mathrm{m}$ in RE and $1.82 \mu \mathrm{m}$ in LE (Table 1 and Table 3). The differences of choroidal thickness between first and third trimester and second and third trimester are statistically significant $(\mathrm{p}=$ .00). However, difference of choroidal thickness between first and second trimester was not statistically significant $(\mathrm{p}=$ $.077)$ in RE and ( $p=.066)$ in LE respectively (Table 2 and Table 4). Mean inferior parafoveal choroidal thickness in RE was $284.72 \mu \mathrm{m}$ (SD- \pm 1.036 , Range $283 \mu \mathrm{m}-286 \mu \mathrm{m}$ ) in first trimester, $285.78 \mu \mathrm{m}$ (SD- \pm 1.031 , Range $284 \mu \mathrm{m}-287 \mu \mathrm{m})$ in second trimester and $283.80 \mu \mathrm{m}$ (SD- \pm 0.985 , Range 282 $\mu \mathrm{m}-285 \mu \mathrm{m}]$ in third trimester. The mean inferior parafoveal choroidal thickness in LE was $284.57 \mu \mathrm{m}$ (SD$\pm 1,027$, Range $283 \mu \mathrm{m}-287 \mu \mathrm{m}$ ) in first trimester, 285.83 
$\mu \mathrm{m}$ (SD- \pm 1.120 , Range $283 \mu \mathrm{m}-288 \mu \mathrm{m}$ ) in second trimester and $283.53 \mu \mathrm{m}$ (SD- \pm 1.167 , Range $281 \mu \mathrm{m}-285 \mu \mathrm{m}$ ) in third trimester, so the mean inferior parafoveal choroidal thickness increased in second trimester in comparison to first trimester by mean of $1.06 \mu \mathrm{m}$ in $\mathrm{RE}$ and $1.26 \mu \mathrm{m}$ in $\mathrm{LE}$, but subsequently decreased in third trimester in comparison to second trimester by mean of $1.98 \mu \mathrm{m}$ in RE and $2.3 \mu \mathrm{m}$ in LE (Table 1 and Table 3 ) and the difference of choroidal thickness was also statistically significant between first and second trimester, second and third trimester and first and third trimester $(\mathrm{p}=.00)$ (Table 2 and Table 4). Mean superior parafoveal choroidal thickness in RE was $285.88 \mu \mathrm{m}$ (SD \pm 1.647 , Range $289 \mu \mathrm{m}-291 \mu \mathrm{m}$ ) in first trimester, 286.88 $\mu \mathrm{m}(\mathrm{SD} \pm 1.616$, Range $284 \mu \mathrm{m} 290 \mu \mathrm{m})$ in second trimester and $284.81 \mu \mathrm{m}$ (SD- \pm 1.7333 , Range $280 \mu \mathrm{m}-288 \mu \mathrm{m}$ ) in third trimester. Mean superior parafoveal choroidal thickness in LE was $285.74 \mu \mathrm{m}(\mathrm{SD} \pm 1.587$, Range $281 \mu \mathrm{m} 289 \mu \mathrm{m})$ in first trimester, $286.88 \mu \mathrm{m}$ (SD \pm 1.616 , Range $284 \mu \mathrm{m} 290 \mu \mathrm{m}$ ) in second trimester and $284.62 \mu \mathrm{m}$ (SD- \pm 1.841 , Range 279 $\mu \mathrm{m}-288 \mu \mathrm{m}$ ) in third trimester. So mean superior parafoveal choroidal thickness increased in second trimester in comparison to first trimester by mean of $1.00 \mu \mathrm{min} R E$ and $1.14 \mu \mathrm{min} L E$, but subsequently decreased in third trimester in comparison to second trimester by mean of $2.07 \mu \mathrm{m}$ in RE and $2.26 \mu \mathrm{m}$ in LE significant (Table 1 and Table 3). The difference of choroidal thickness was also significant between first and second trimester, second and third trimester and first and third trimester $(\mathrm{p}=.00)$ (Table 2 and Table 4). The mean nasal parafoveal choroidal thickness in RE was 276.76 $\mu \mathrm{m}$ (SD- \pm 3.432 , Range $270 \mu \mathrm{m}-282 \mu \mathrm{m}$ ) in first trimester, $277.83 \mu \mathrm{m}$ (SD- \pm 3.300 , Range $272 \mu \mathrm{m}-283 \mu \mathrm{m}$ ) in second trimester and $275.72 \mu \mathrm{m}$ (SD- \pm 3.545 , Range $270 \mu \mathrm{m}-281$ $\mu \mathrm{m})$ in third trimester. The mean nasal parafoveal choroidal thickness in LE was $276.31 \mu \mathrm{m}$ (SD- \pm 3.142 , Range $270 \mu \mathrm{m}-$ $281 \mu \mathrm{m}$ ) in first trimester, $277.83 \mu \mathrm{m}$ (SD- \pm 3.300 , Range 272 $\mu \mathrm{m}-283 \mu \mathrm{m}$ ) in second trimester and $275.57 \mu \mathrm{m}$ (SD\pm 3.696 , Range $270 \mu \mathrm{m}-282 \mu \mathrm{m}$ ) in third trimester. So the mean nasal parafoveal choroidal thickness also significantly increased in second trimester in comparison to first trimester by mean of $1.07 \mu \mathrm{m}$ in RE and $1.52 \mu \mathrm{m}$ in LE, but subsequently decreased in third trimester in comparison to second trimester by mean of $2.11 \mu \mathrm{m}$ in RE and $2.26 \mu \mathrm{m}$ in LE (Table 1 and Table 3), and the difference of the mean nasal parafoveal choroidal thickness is statistically significant in both eyes between first and second and second and third trimester $(\mathrm{p}=.00)$.

However, that the difference between first and third trimester was not significant $(p=.065)$ in RE and $(p=.305)$ in LE (Table 2 and Table 4). We reported that the mean temporal parafoveal choroidal thickness in RE was 292.75 $\mu \mathrm{m}$ (SD- \pm 1.672 , Range $290 \mu \mathrm{m}-295 \mu \mathrm{m}$ ) in first trimester, $293.25 \mu \mathrm{m}$ (SD- \pm 1.777 , Range $289 \mu \mathrm{m}-296 \mu \mathrm{m}$ ) in second trimester and $291.81 \mu \mathrm{m}$ (SD- \pm 1.674 , Range $289 \mu \mathrm{m}-294$ $\mu \mathrm{m})$ in third trimester. Mean temporal parafoveal choroidal thickness in LE was $292.86 \mu \mathrm{m}$ (SD- \pm 1.670 , Range $290 \mu \mathrm{m}-$ $296 \mu \mathrm{m}$ ) in first trimester, $293.45 \mu \mathrm{m}$ (SD- \pm 1.777 , Range 289 $\mu \mathrm{m}-296 \mu \mathrm{m}$ ) in second trimester and $291.57 \mu \mathrm{m}$ (SD\pm 1.677 , Range $\pm 288 \mu \mathrm{m}-294 \mu \mathrm{m}$ ) in third trimester. So mean temporal parafoveal choroidal thickness also increased in second trimester in comparison to first trimester by mean of $0.05 \mu \mathrm{m}$ in RE and $0.59 \mu \mathrm{m}$ in LE, but it decreased in third trimester in comparison to second trimester by mean 1.44 $\mu \mathrm{m}$ in RE and $1.88 \mu \mathrm{m}$ in LE (Table 1 and Table 3 ) and the difference of mean temporal parafoveal choroidal thickness was significant between first and third trimester $(p=.00)$, second and third trimester $(\mathrm{p}=.00)$. However, the difference of mean temporal parafoveal choroidal thickness was not significant between first and second trimester $(p=.104)$ in $\mathrm{RE}$, but the difference is significant between first and second trimester, second and third trimester and first and third trimester in LE (Table 2 and Table 4).

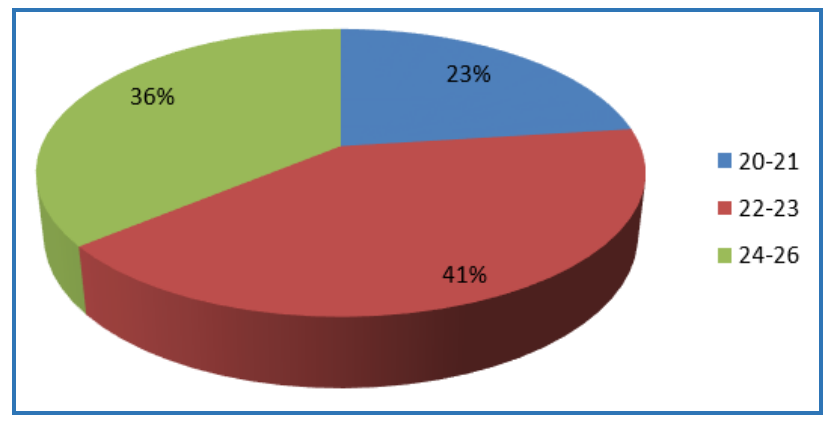

Fig. 3: Pie Chart showing the Age Distribution of Pregnant Women

\begin{tabular}{|c|c|c|c|c|c|}
\hline Trimester & \multicolumn{5}{|c|}{ Choroidal Thickness in Right Eye (Mean \pm SD) (In $\boldsymbol{\mu m}$ ) } \\
\hline & Subfoveal & Inferior & Superior & Nasal & Temporal \\
\hline First & $308.30 \pm 2.096$ & $284.72 \pm 1.036$ & $285.88 \pm 1.647$ & $276.76 \pm 3.432$ & $292.75 \pm 1.672$ \\
\hline Second & $308.93 \pm 2.011$ & $285.78 \pm 1.031$ & $286.88 \pm 1.616$ & $277.83 \pm 3.300$ & $293.25 \pm 1.777$ \\
\hline Third & $307.62 \pm 2.024$ & $283.80 \pm 0.985$ & $284.81 \pm 1.733$ & $275.72 \pm 3.545$ & $291.81 \pm 1.674$ \\
\hline \multicolumn{7}{|l|}{ Table 1: Choroidal Thickness in Uncomplicated Pregnancy in Different Trimester in Different Quadrants in Right Eye } \\
\hline
\end{tabular}

\begin{tabular}{|c|c|c|c|}
\hline Choroidal Thickness & 1 $^{\text {st }}$ vs 2nd Trimester & 2 $^{\text {nd }}$ vs 3rd Trimester & 1 $^{\text {st }}$ vs 3rd Trimester \\
\hline Subfoveal & .077 & .00 & .00 \\
\hline Inferior & .00 & .00 & .00 \\
\hline Superior & .00 & .00 & .00 \\
\hline Nasal & .00 & .00 & .065 \\
\hline Temporal & .104 & .00 & .00 \\
\hline \multicolumn{2}{|r|}{ Table 2: Statistical Significance of Choroidal Thickness in Different Trimester at Different Points in Right Eye } \\
\hline
\end{tabular}




\begin{tabular}{|c|c|c|c|c|c|}
\hline Trimester & \multicolumn{5}{|c|}{ Choroidal Thickness in Left Eye Mean \pm SD (In $\boldsymbol{\mu m}$ ) } \\
\hline & Subfoveal & Inferior & Superior & Nasal & Temporal \\
\hline First & $308.29 \pm 2.007$ & $284.57 \pm 1.027$ & $285.74 \pm 1.587$ & $276.31 \pm 3.142$ & $292.86 \pm 1.670$ \\
\hline Second & $308.95 \pm 1.925$ & $285.83 \pm 1.120$ & $286.88 \pm 1.616$ & $277.83 \pm 3.300$ & $293.45 \pm 1.777$ \\
\hline Third & $307.13 \pm 2.338$ & $283.53 \pm 1.167$ & $284.62 \pm 1.841$ & $275.57 \pm 3.696$ & $291.57 \pm 1.677$ \\
\hline \multicolumn{6}{|r|}{ Table 3: Choroidal Thickness in Uncomplicated Pregnancy in Different Trimester in Different Quadrants in Left Eye } \\
\hline
\end{tabular}

\begin{tabular}{|c|c|c|c|}
\hline $\begin{array}{c}\text { Choroidal } \\
\text { Thickness }\end{array}$ & $\begin{array}{c}\text { 1st }^{\text {st }} \mathbf{2}^{\text {nd }} \\
\text { Trimester }^{\text {simd }}\end{array}$ & $\begin{array}{c}\mathbf{2}^{\text {nd }} 3^{\text {rd }} \\
\text { Trimester }\end{array}$ & $\begin{array}{c}\text { 1st vs 3rd }^{\text {rd }} \\
\text { Trimester }\end{array}$ \\
\hline Subfoveal & .066 & .00 & .00 \\
\hline Inferior & .00 & .00 & .00 \\
\hline Superior & .00 & .00 & .001 \\
\hline Nasal & .00 & .00 & .305 \\
\hline Temporal & .037 & .00 & .00 \\
\hline
\end{tabular}

Table 4: Statistical Significance of Choroidal Thickness in Different Trimester at Different Points in Left Eye

\section{DISCUSSION}

The present study reports that the mean subfoveal and parafoveal ( $3 \mathrm{~mm}$ away from fovea in inferior, superior, nasal and temporal quadrant) choroidal thickness in both eyes significantly increases in second trimester in comparison to first trimester, but gradually decreases in third trimester in comparison to second trimester. One study reported choroidal thickening occur at the regions subfoveal, temporal and nasal to the fovea in the second trimester, but did not notice any increase in choroidal thickness in first and third trimester which is in contradiction to our study. Numerous study6 reported subfoveal and parafoveal choroidal thickness on healthy and pregnant women in third trimester and found no statistically significant difference. Another study reported 100 healthy pregnant women as study group and opined that SFCT was significantly thicker in normal pregnant women in comparison to non-pregnant women.

Numerous study reported that changes in choroidal thickness in last trimester of trimester are more pronounced when serum corticosteroid reaches its highest level from placenta and developing foetus that influences choroidal function by altering the production of free radicals, prostaglandins and Nitric Oxide (NO) with impairment of choroidal vascular autoregulation. This may lead to abnormalities in blood pressure in the choriocapillaries and result in hyperpermeability of choroid. The effect of nitric oxide/cyclic guanosine monophosphate (NO/CGMP) cascade on the structure of choroid results in increased capillary fragility and permeability. It is postulated that if the tissue hydrostatic pressure induced by hyperpermeable choroidal vessels is enough to produce damaged RPE, then it is expected that the choroidal thickness itself will be increased in third trimester. Other study reported increased SFCT in third trimester in their study of 29 healthy pregnant in third trimester.

In our study, we report that the subfoveal and parafoveal choroidal thickness significantly decreases in third trimester in comparison to second trimester as choroid is a vascular compartment which plays an important role in intraocular pressure regulation, temperature control and ocular nutrition. ${ }^{1}$ A high volume from $65 \%$ to $85 \%$ of ocular blood flows through choroid in pregnancy. During pregnancy, the maternal choroid is exposed to haemodynamic and hormonal alterations inherent to this physiological condition. ${ }^{1}$ During gestation, there is decrease in vascular resistance from the fifth week of gestation and drop in arterial pressure in midpregnancy and increase in cardiac output and resting pulse rate. In mid-pregnancy, there is increase in renin angiotensin level which produce an expansion of blood volume of upto $45 \%$ due to water retention and a decrease in colloid osmotic pressure. Since the choroid is primarily a vascular compartment, the haemodynamic changes of pregnancy may influence the choroidal shape. ${ }^{5}$

All these factors are responsible for increased choroidal thickness in second trimester. 6 As pregnancy progresses, blood flow increases in many organs including kidneys, extremities and skin due to vasodilatation by oestrogen in third trimester, peripheral pooling of blood and decrease in choroidal blood flow. Plasma volume expansion increases by $40 \%$ in last trimester, as there is 10 fold increase in oestradiol and progesterone at around 36 weeks. This could lead to decreased choroidal thickness in third trimester.

\section{CONCLUSION}

The present study reports that the mean subfoveal and parafoveal ( $3 \mathrm{~mm}$ away from fovea) in inferior, superior, nasal and temporal quadrant choroidal thickness increases in second trimester in comparison to first trimester due to decreased peripheral vascular resistance, (Peak decrease at 6-8 weeks of pregnancy) renin-angiotensin induced salt water retention from fifth week of gestation, but as the pregnancy progresses the choroidal thickness significantly decreases in third trimester in comparison to second trimester due to oestrogen-induced peripheral vasodilatation, peripheral pooling of blood and decreased choroidal blood flow. In third trimester, choroid may be subjected to physiological changes in structure.

\section{REFERENCES}

1. Sunness JS. The pregnant woman's eye. Surv Ophthalmol 1998;32(4):219-38.

2. Chew EY, Mills JL, Metzger BE, et al. Metabolic control and progressing retinopathy. The diabetes in early pregnancy study. National institute of child health and human development diabetes in early pregnancy study. Diabetic Case 1995;18(5):631-7.

3. Sunnes JS, Haller JA, Fine SL. Central serous chorioretinopathy and pregnancy. Arch Ophthalmol 1993;111(3):360-4.

4. Burke JP, Whyte I, MacEwen CJ. Bilateral serous retinal detachments in the HELLP syndrome. Acta Ophthalmol 1989;67(3):322-4.

5. Garg P, Aggarwal P. Ocular changesin pregnancy. Nepal J Ophthalmol 2012;4(1):150-61.

6. Takahasi J, Kado M, Mizumoto $\mathrm{K}$, et al. Choroidal thicknessin pregnant women measured by enhanced depth imaging optical coherence tomography. Jpn J Ophthalmol 2013;57(5):435-9. 